\title{
Basal cell carcinoma arising in port wine stains: coincidence or correlation?
}

\author{
Iwona Chlebicka, Aleksandra Stefaniak, Andrzej Bieniek, Jacek Szepietowski
}

Department of Dermatology, Venereology and Allergology, Wroclaw Medical University, Wroclaw, Poland

Adv Dermatol Allergol 2020; XXXVII (2): 272-273

DOI: https://doi.org/10.5114/ada.2020.93683

Basal cell carcinoma (BCC) developing in port wine stains (PWS) has rarely been reported in the literature [1]. Most of those patients were treated in childhood with radiotherapy for PWS [2]. On the other hand there is an ongoing discussion on possible connections between BCC and PWS [1-3]. A port wine stain is a vascular anomaly which is present at birth and persists during life. It occurs in $0.3 \%$ of neonates [3]. Basal cell carcinoma is the most common type of skin cancer, and it usually affects elderly patients [4, 5]. There are few well-documented risk factors for developing BCC such as sun exposure and ionizing radiation treatment [5].

Here, we present 5 cases of BCC in PWS in middleaged female patients not treated with radiotherapy for PWS previously. It seems that this is a biggest case series of BCC in PWS collected from one surgical centre and the third report documenting BCC in PWS in a non-facial area [3].

During the last 10 years (2008-2017) five patients with BCC in the PWS were surgically treated. All patients were middle-aged Caucasian females (48-67 years old). All the cases presented with a clinical nodular type of BCC with ulceration present in the centre in two of them. In four of them BCC was located on the face and in one on the abdomen. They were all located within PWS, however in one patient the BCC was located peripherally. The duration of the BCC development before the admission to the hospital was 6-26 months. As the clinical diagnosis was very suggestive for BCC the lesions were removed surgically and in 4 of them finalized with primary closure. In one patient the local flap was employed. There were no problems with bleeding during the surgery. In all the patients postsurgical recovery was without any complications. The histological diagnosis of BCC was confirmed in all patients (Table 1, Figures 1-3).

Basal cell carcinoma arising in port wine stains has been rarely described in the literature. We were able to find about 30 reported cases in the available database (in 1948-2018). Most of the documented cases (approximately $75 \%$ ) were associated with radiotherapy for PWS usually many years before the BCC development [1]. To the best of our knowledge, there are only eight described cases of BCC arising in PWS in patients without any prior therapy. All of them are single case reports from different European and Asian surgical centres and most of them have been reported in recent years [2]. Beyond prior radiation therapy (such as thorium X, Grenz ray and the topical radiotherapy), sun light exposure, Fitzpatrick skin type 1 and 2 and advanced age might also be considered as risk factors for developing BCC in PWS [3].

In our patients, we cannot consider advanced age as a crucial risk factor. It is more likely that the sun light

Table 1. Demographic and clinical details of patients with BCC in PWS

\begin{tabular}{lcccccc}
\hline $\begin{array}{l}\text { No. of } \\
\text { case }\end{array}$ & Sex & Age & Site of BCC & Diameter of BCC [mm] & Previous therapy for PWS & $\begin{array}{c}\text { Type of surgical procedure } \\
\text { for BCC }\end{array}$ \\
\hline 1 & F & 64 & Nose & 14 & No & Local flap \\
\hline 2 & F & 48 & Upper lip & 9 & No & Primary closure \\
\hline 3 & F & 45 & Left cheek & 11 & No & Primary closure \\
\hline 4 & F & 67 & Left cheek & 12 & No & Primary closure \\
\hline 5 & F & 60 & Abdomen & 15 & &
\end{tabular}

BCC - basal cell carcinoma, PWS - port wine stain.

Address for correspondence: Dr. Iwona Chlebicka, Department of Dermatology, Venereology and Allergology, Wroclaw Medical University, 1 Chałubińskiego St, Wroclaw, Poland, phone: +48 7178422 91, e-mail: iwonak4wsk@interia.pl Received: 9.11.2018, accepted: 19.11.2018. 


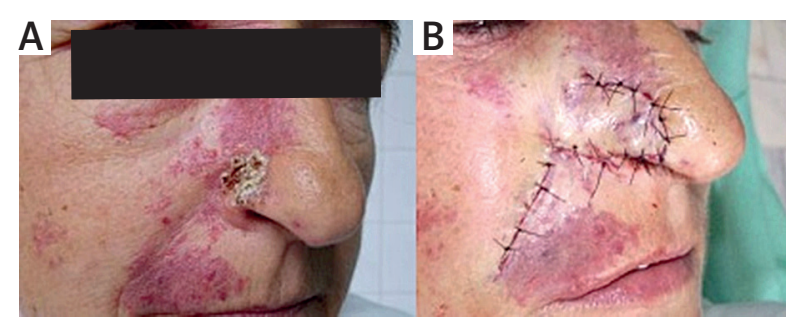

Figure 1. Patient no. 1. Before (A) and after (B) the surgical treatment with a local flap procedure

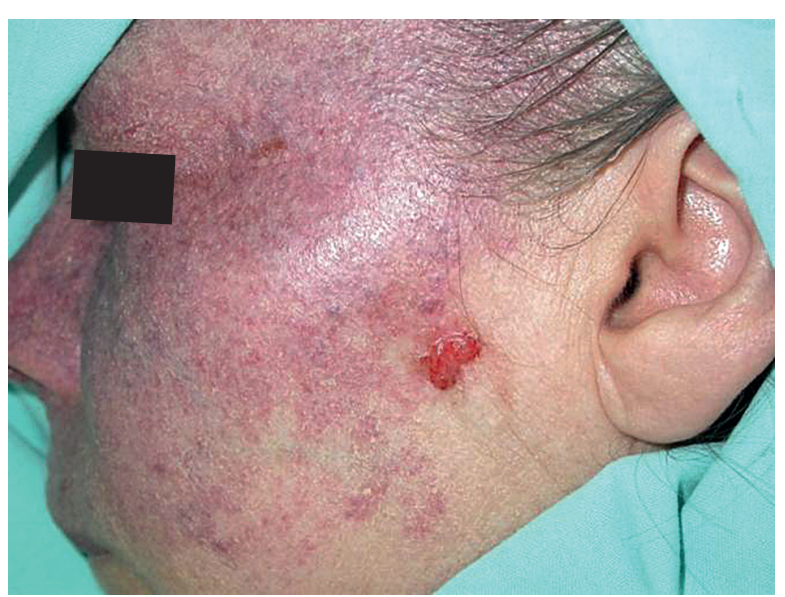

Figure 3. Patient no. 3. Basal cell carcinoma located peripherally within port wine stain

exposure and Fitzpatrick skin type played a role. On the other hand, some additional factors, which were postulated in the literature, i.e. anomalous vessels in PWS producing perhaps oncogenic factors which make skin more sensitive for ultraviolet, could be discussed [4].

Treatment of BCC in PWS may be difficult and it is of importance to pay attention to possibility of bleeding and formation of postoperative hematoma. In all our patients we did not observe any above mentioned complications.

In conclusion, we would like to raise awareness that the patients with PWS might be considered as a group of risk for the development of BCC, especially those with previous radiotherapy, but also younger patients with extensive sun exposure and Fitzpatrick skin type 1 and 2. We recommend high sun protection for all patients with PWS as well as frequent dermatological screening for BCC. The surgery of BCC in PWS should be the treatment of choice. In some very selected cases of BCC in PWS, especially in patients with a high risk of perioperative bleeding, it is possible to use optional treatment with combined $\mathrm{CO}_{2}$ laser and photodynamic therapy [5].

\section{Conflict of interest}

The authors declare no conflict of interest.

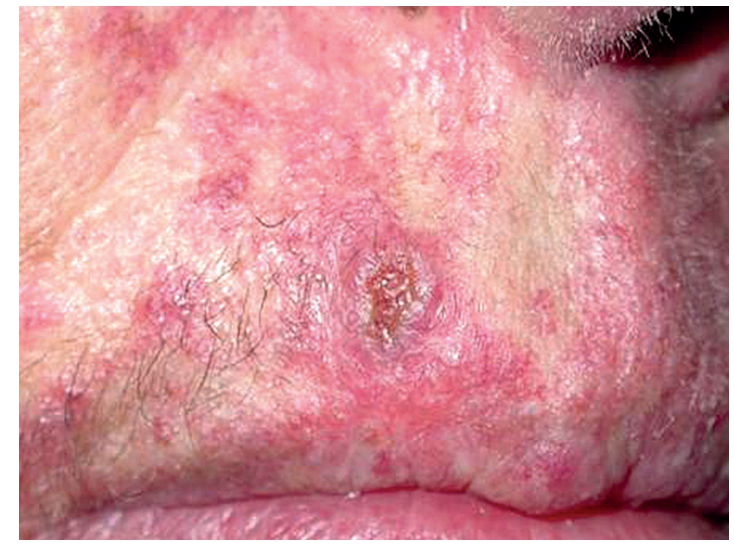

Figure 2. Patient no. 2. Typical ulcerated nodular type of basal cell carcinoma in the port wine stain

\section{References}

1. Lapidoth M, Ad-El D, David M, et al. Basal cell carcinoma arising over facial port wine stain: a single-centre experience. J Eur Acad Dermatol Venereol 2006; 20: 1066-9.

2. Hackett CB, Langtry JA. Basal cell carcinoma of the ala nasi arising in a port wine stain treated using mohs micrographic surgery and local flap reconstruction. Dermatol Surg 2014; 40: 590-2.

3. Kaune KM, Haas E, Buhl T, et al. Multiple basal cell carcinomas arising in radiotherapy-treated nevus flammeus: early detection facilliated by 595-nm pulsed dye laser. Eur J Dermatol 2010; 20: 510-1.

4. Natkunarajah J, Cliff S. Thorium X treatment: multiple basal cell carciomas within a port-wine stain. Clin Exp Dermatol 2009; 34: 189-91.

5. Javed MU, Murison M. The combined $\mathrm{CO}_{2}$ laser and photodynamic therapy of multiple BCC's in a facial port wine stain. J Plast Reconstr Aesthet Surg 2016; 69: 10-2. 